\title{
Correction to: Enhancing the sustainability science agenda through Indigenous methodology
}

\author{
Diane Ruwhiu ${ }^{1}$ (1) Hitaua Arahanga-Doyle ${ }^{2} \cdot$ Roma Donaldson-Gush ${ }^{3} \cdot$ Corey Bragg ${ }^{4} \cdot J^{-}$anine Kapa ${ }^{5}$. \\ Kāti Huirapa Rūnaka ki Puketeraki ${ }^{6}$
}

Published online: 19 November 2021

๑) Springer Japan KK, part of Springer Nature 2021

\section{Correction to: Sustainability Science https://doi.org/10.1007/s11625-021-01054-2}

In the original publication of the article, the last author name was missing and included in this correction.

The last author name is "Kāti Huirapa Rūnaka ki Puketeraki" and the respective affiliation is "Karitāne, Dunedin, Aotearoa New Zealand".

In addition, affiliations of following authors "Hitaua Arahanga-Doyle and Roma Donaldson-Gush" were incorrect. The correct affiliations are provided below,

The original article can be found online at https://doi.org/10.1007/ s11625-021-01054-2.

Diane Ruwhiu

diane.ruwhiu@otago.ac.nz

1 Department of Management, University of Otago, PO Box 56, Dunedin 9054, New Zealand

2 Department of Psychology, University of Otago, Dunedin, New Zealand

3 Te Tumu School of Māori, Pacific and Indigenous Studies, University of Otago, Dunedin, New Zealand

4 Te Rūnaka o Awarua, Bluff, New Zealand

5 Otago Polytechnic, Dunedin, New Zealand

6 Karitāne, Dunedin, New Zealand
Affiliation 2: Department of Psychology, University of Otago, New Zealand

Affiliation 3: Te Tumu School of Māori, Pacific and Indigenous Studies, University of Otago, New Zealand

The original article was updated.

Publisher's Note Springer Nature remains neutral with regard to jurisdictional claims in published maps and institutional affiliations. 